\title{
INTELIGÊNCIA ARTIFICIAL NO JUDICIÁRIO BRASILEIRO: A CONSTRUÇÃO DE UM MODELO PARA EFETIVAÇÃO DE DIREITOS E GARANTIAS INDIVIDUAIS
}

\section{ARTIFICIAL INTELLIGENCE IN BRAZILIAN JUDICIARY: A CONSTRUCTION OF A MODEL FOR IMPLEMENTATION OF RIGHTS AND INDIVIDUAL GUARANTEES}

RICARDO WYPYCH Mestrando em Direito Empresarial e Cidadania pelo Centro Universitário de Curitiba UNICURITIBA (2018), pós-graduado em Direito Aplicado pela Escola da Magistratura do Paraná - EMAP (2012), pós-graduando em Direito Processual Civil pelo Instituto de Direito Bacellar (2018), graduado em Direito pela Pontifícia Universidade Católica do Paraná - PUC/PR(2011).

\section{RESUMO}

O poder judiciário deve atender os anseios da sociedade em que está inserido, de modo a dar a todos os envolvidos, uma possibilidade célere de pacificação dos conflitos. Neste sentido, é dever do Estado buscar o auxílio das novas tecnologias para o aumento da eficiência na prestação de seus serviços. A pesquisa acadêmica, a produção de conhecimento e a atuação na incorporação de inovações tecnológicas antes distantes do Poder Judiciário, atualmente são temas corriqueiros de discussão nos tribunais. As tecnologias de Inteligência Artificial podem proporcionar os objetivos aguardados pelos jurisdicionados, ou seja, a redução de custos da operação do judiciário com maior celeridade e razoabilidade na duração de processos judiciais, por 


\section{Personalidade Acadêmica Homenageada:}

\section{Augustus B. Cochran III (Agnes Scott College)}

outro lado, também apresentam consequências morais e práticas, na medida em que, inexoravelmente, assumem complexidade e protagonismo na tomada de decisões jurisdicionais. Nesse contexto, o presente artigo busca identificar os princípios filosóficos e doutrinários que justificam tais medidas, alertando para a necessidade de salvaguardas éticas em sua implementação. Para que se alcance o melhor resultado com a temática em tela, se faz necessário a pesquisa bibliográfica pelo método dedutivo e pesquisa de campo, dos programas existentes no judiciário estadual paranaense, onde Equipes do Departamento de Tecnologia da Informação e Comunicação (DTIC) do Tribunal de Justiça do Paraná (TJPR), que buscam identificar as necessidades de automação e IA em cada atividade da instituição, a fim de criar sistemas capazes de aplicar a tecnologia1, bem como àqueles utilizados nos tribunais superiores, em especial o VICTOR do STF. Após o aprofundamento das práticas atuais do judiciário nacional, será contraposto com a realidade no cotidiano forense, verificando então se tais medidas são válidas para se alcançar o objetivo maior de proteção dos direitos e garantias individuais.

O estudo ainda não possui dados concretos que possibilitem o alcance de uma conclusão certeira, que pudesse dar novos rumos as rotinas judiciais, resultando em melhor satisfação dos jurisdicionados. Mas uma coisa é certa, somente com a concretização da pesquisa, poder-se-á atingir resultados outrora não observados pelos operadores do direito, o que reflete de maneira positiva a importância do caso concreto. Todos merecem um judiciário ativo, enxuto, inteligente e tecnológico, evitando a morosidade que invade a seara das relações postas para apreciação jurisdicional, pois somente neste caminho, se concretizará as garantias constitucionais conquistadas ao longo de tantos anos.

Palavras-chave: Poder Judiciário; inteligência artificial; ética.

\footnotetext{
1 https://www.tjpr.jus.br/destaques/-/asset_publisher/1IKI/content/tecnologia-a-favor-da-justica-tjprdesenvolve-sistemas-de-inteligenciaartificial/18319?inheritRedirect=false\&amp;redirect=https\%3A\%2F\%2Fwww.tjpr.jus.br\%2Fdestaques \%3Fp_p_id\%3D101_INSTANCE_1IKI\%26p_p_lifecycle\%3D0\%26p_p_state\%3Dnormal\%26p_p_mod e\%3Dview\%26p_p_col_id\%3Dcolumn-2\%26p_p_col_count\%3D1
} 
Personalidade Acadêmica Homenageada:

Augustus B. Cochran III (Agnes Scott College)

\section{REFERÊNCIAS}

BOTELHO, Fernando Neto. 0 processo eletrônico escrutinado. UFSC: Florianópolis, SC, 2007

BRASIL. Lei 11.419 de 19 de dezembro de 2006. Disponível em: http://www.planalto.gov.br/ccivil_03/_ato2004-2006/2006/lei//11419.htm. Acesso em: 04 jun. 2019.

CALDAS, Roberto Correia da Silva Gomes, DIZ, Jamile Bergamaschine Mata, SILVA, Antonio Donizete Ferreira da. Governança e as novas tecnologias: a sustentabilidade na gestão administrativa do poder judiciário. Revista Jurídica e-ISSN: 2316-753X, vol. 01, n. 54, Curitiba, 2019. pp. 364 - 394. DOI: 10.6084/m9.figshare.7841144

CASTELLS, Manuel. A Era da Informação: Economia, Sociedade e Cultura Vol. 1 O Poder da Identidade. São Paulo, Ed. Paz e Terra, 1999.

CONSELHO NACIONAL DE JUSTIÇA. Portaria № 25 de 19/02/2019. Disponível em: <http://www.cnj.jus.br/atos-normativos?documento=2829> Acesso em: 05 abr. 2019.

ELIAS, Paulo de Sá. Algoritmos e inteligência artificial exigem atenção do Direito. Disponível em: <https://www.conjur.com.br/2017-nov-20/paulo-sa-elias-inteligenciaartificial-requer-atencao-direito> Acesso em: 05 abr. 2019

KRAMMES, Alexandre Golin. Aplicação de Workflow em Processos Judiciais Eletrônicos, 2008, 124. Dissertação (Mestrado em Engenharia e Gestão do Conhecimento) - Programa de Pós-Graduação em Engenharia e Gestão do Conhecimento, UFSC, Florianópolis

KULSTAD, Mark. CARLIN, Laurence. Leibniz's Philosophy of Mind. Disponível em em: <https://plato.stanford.edu/entries/leibniz-mind/> Acesso em: 05 abr. 2019

PESSERL, Alexandre Ricardo. A Biblioteca pública digital: direito autoral e acesso na sociedade informacional. Dissertação de mestrado. UFSC: Florianópolis, SC, 2011.

RIFKIN, Jeremy. A era do acesso. São Paulo: Makron Books, 2005

ROVER, Aires José. O governo eletrônico e a inclusão digital: duas faces da mesma moeda chamada democracia. In ROVER, A.J. (org). Inclusão digital e governo eletrônico. UFSC: Florianópolis, SC, 2008. 